\title{
THE PRC's LONG-RUN GROWTH THROUGH THE LENS OF THE EXPORT-LED GROWTH MODEL
}

Jesus Felipe and Matteo Lanzafame

NO. 555

August 2018
ADB ECONOMICS WORKING PAPER SERIES 


\section{The PRC's Long-Run Growth through the Lens of the Export-Led Growth Model}

Jesus Felipe and Matteo Lanzafame

No. 555 | August 2018
Jesus Felipe (jfelipe@adb.org) is an Advisor in the Economic Research and Regional Cooperation Department of the Asian Development Bank. Matteo Lanzafame (mlanzafame@unime.it) is an Associate Professor in the Department of Economics at the Università degli Studi di Messina.

We are grateful to Yasu Sawada for his comments and suggestions. 
(C) 2018 Asian Development Bank 6 ADB Avenue, Mandaluyong City, 1550 Metro Manila, Philippines

Tel +632632 4444; Fax +6326362444

www.adb.org

Some rights reserved. Published in 2018.

ISSN 2313-6537 (print), 2313-6545 (electronic)

Publication Stock No. WPS189511-2

DOI: http://dx.doi.org/10.22617/WPS189511-2

The views expressed in this publication are those of the authors and do not necessarily reflect the views and policies of the Asian Development Bank (ADB) or its Board of Governors or the governments they represent.

ADB does not guarantee the accuracy of the data included in this publication and accepts no responsibility for any consequence of their use. The mention of specific companies or products of manufacturers does not imply that they are endorsed or recommended by ADB in preference to others of a similar nature that are not mentioned.

By making any designation of or reference to a particular territory or geographic area, or by using the term "country" in this document, $A D B$ does not intend to make any judgments as to the legal or other status of any territory or area.

This work is available under the Creative Commons Attribution 3.0 IGO license (CC BY 3.0 IGO)

https://creativecommons.org/licenses/by/3.o/igo/. By using the content of this publication, you agree to be bound by the terms of this license. For attribution, translations, adaptations, and permissions, please read the provisions and terms of use at https://www.adb.org/terms-use\#openaccess.

This CC license does not apply to non-ADB copyright materials in this publication. If the material is attributed to another source, please contact the copyright owner or publisher of that source for permission to reproduce it. $\mathrm{ADB}$ cannot be held liable for any claims that arise as a result of your use of the material.

Please contact pubsmarketing@adb.org if you have questions or comments with respect to content, or if you wish to obtain copyright permission for your intended use that does not fall within these terms, or for permission to use the ADB logo.

Notes:

In this publication, “\$” refers to United States dollars.

ADB recognizes "China" as the People's Republic of China; and "Hong Kong" as Hong Kong, China.

Corrigenda to ADB publications may be found at http://www.adb.org/publications/corrigenda. 


\section{CONTENTS}

TABLES AND FIGURES

$\begin{array}{ll}\text { I. INTRODUCTION } & 1\end{array}$

II. THE BALANCE-OF-PAYMENTS EQUILIBRIUM GROWTH RATE MODEL 3

III. ESTIMATION RESULTS OF THE PEOPLE'S REPUBLIC OF CHINA'S TIME-VARYING BALANCE-OF-PAYMENTS EQUILIBRIUM GROWTH RATE

IV. HOW RELEVANT IS THE BALANCE-OF-PAYMENTS EQUILIBRIUM GROWTH RATE FOR THE PEOPLE'S REPUBLIC OF CHINA?

A. Was the People's Republic of China's Growth Significantly Different from Its Balance-of-Payments Equilibrium Growth Rate?

B. Does the Balance-of-Payments Equilibrium Growth Rate Cause the Actual Growth Rate? A Vector Autoregression Analysis

V. THE DETERMINANTS OF THE PEOPLE'S REPUBLIC OF CHINA'S BALANCE-OFPAYMENTS EQUILIBRIUM GROWTH RATE AND THE INCOME ELASTICITY OF IMPORTS: A BAYESIAN MODEL AVERAGING APPROACH

VI. CONCLUSIONS 


\section{TABLES AND FIGURES}

\section{TABLES}

1 Tests of Hypotheses I, II, and III

2 Granger-Causality Tests for the Relationship between $y_{B t}$ and $y_{t}^{T}$

3 Variables and Data Sources

4 Bayesian Model Averaging Estimates of Robust Determinants of $y_{B t}$ 20

5 Bayesian Model Averaging Estimates of Robust Determinants of $\hat{\pi}_{t}$

\section{FIGURES}

$1 \quad$ Growth Rates of the Volumes of Exports and Imports

2 Estimated Income Elasticity of Imports and Trend Growth Rate of Exports of the People's Republic of China, 1981-2016

3 Actual, Trend, and Balance-of-Payments Equilibrium Growth Rates of the People's Republic of China, 1981-2016

$4 \quad$ Estimated Impulse Response Function to a One Standard Deviation Shock in $y_{B t} \quad 15$

5 Estimated Impulse Response Functions to a One Standard Deviation Shock in $x_{t}^{T}$ and $\hat{\pi}_{t} \quad 16$ 


\begin{abstract}
The People's Republic of China's (PRC) remarkable growth performance over the last 3 decades has been associated to very robust export growth, so much so that many refer to it as a clear example of export-led growth (ELG). Using the concept of the balance-of-payments equilibrium (BOPE) growth rate, which provides a framework to test the ELG hypothesis, we show that the PRC's actual long-run growth is well approximated by its BOPE growth rate. This growth rate is given by the ratio of the growth rate of exports to the income elasticity of imports. We estimate the latter using the Kalman filter, which allows us to obtain a time-varying estimate of the PRC's BOPE growth rate. We find that the average value of the PRC's BOPE growth rate during 1981-2016 was 11\%, but it varied significantly over time and declined notably after 2007. Today, it is estimated at a much lower $5.9 \%$. We then discuss the determinants of the PRC's BOPE growth rate and of the income elasticity of imports, with the help of the Bayesian model averaging technique. The analysis highlights the role of the composition of aggregate demand as the main driving force, both for its direct effects on the income elasticity of imports, and for the indirect effects on export growth via capital accumulation, in particular fixed asset investment. Our analysis has important implications to understand the PRC's transition to a "New Normal" of a lower growth rate.
\end{abstract}

Keywords: balance-of-payments equilibrium growth rate, Bayesian model averaging, export-led growth, Kalman filter, People's Republic of China

JEL codes: $\mathrm{E} 24, \mathrm{E} 32, \mathrm{O} 14, \mathrm{O} 47, \mathrm{O} 50$ 


\section{INTRODUCTION}

There is by now a wide body of literature that has studied the People's Republic of China's (PRC) growth. Most of this literature has used standard growth accounting decompositions of overall growth into the contributions of the growth rates of labor, capital, and total factor productivity (TFP). Most growth analyses gravitate around discussions of the contribution to gross domestic product (GDP) growth of residually estimated TFP growth versus that of capital accumulation. Most studies tend to conclude that the latter contributed significantly to the PRC's GDP growth (the investment-to-GDP ratio reached about 50\%), although the size of the contribution varies across studies and periods considered.' Some studies found that the contribution of TFP growth is small, but very likely technical progress was embodied in capital, or technical progress was biased with an elasticity of substitution less than one, in which case standard TFP growth calculations lead to incorrect (too small) estimates of the latter (Felipe and McCombie 2001, 2002). The drawback of these growth accounting exercises is that they are not a model and, consequently, do not prove causality (Aghion and Howitt 2007), although many researchers clearly draw implications from them and argue in terms of causality from capital, labor, and TFP growth, to output growth. It is important to note that these analyses offer a supply-side explanation of growth (i.e., through the factors of production), and the implicit assumption is that growth is supply constrained, and hence determined by the growth of supply.

While the role of capital accumulation in the PRC's growth is undeniable, and certainly there has been significant technical progress (however measured), the country's remarkable growth performance over the last 3 decades has also been associated to a very robust growth of exports, so much so that many refer to it as a clear example of export-led growth (ELG). ${ }^{2}$ The standard literature on ELG has focused exclusively on the role of exports (e.g., Yao 2018, pp. 42-44), either by estimating the growth effect associated to them (Tingvall and Ljungwall 2012), or by estimating price and income export elasticities in export functions (Ang, Madsen, and Robertson 2015). As we shall argue below, we think that, in practice, the ELG model is much more than this.

The above means that there are powerful reasons why exports matter, and these provide the rationale for why countries gain by following an ELG strategy (McCombie and Thirlwall 1994). Of relevance to us is the fact that exports are the only component of demand that can pay for the import requirement of growth. Surely an economy can experience consumption-led, investment-led, or government expenditure-led growth; but each of these components of demand has an import content. $^{3}$ If an economy does not obtain sufficient export earnings to pay for its imports (more precisely, the import content of other components of expenditure), then demand will have to be

Examples are: Tsui, Hsueh, and Rawski (1995); Borensztein and Ostry (1996); Hu and Khan (1997); Young (2000); Heytens and Zebregs (2003); Islam, Dai, and Sakamoto (2006); Brandt and Zhu (2010); Lin and Zhang (2015). See also the edited volume by Lin, Morgan, and Wan (2018a). Chow (1993) used regression analysis to estimate TFP growth. See Chow (2006) and Holz (2006) exchange on the construction of capital stocks for the PRC.

2 See, for example, the PRC's improvement in the economic complexity index elaborated by the Center for International Development (http://atlas.cid.harvard.edu/).

3 Exports are the only component of "autonomous" demand in an economy, in the sense that their demand emanates outside the economy. On the other hand, the major part of consumption and investment demand depends on the growth of income itself. Second, imports may be more productive than domestic resources because certain crucial goods for development, e.g., capital goods, are not produced domestically. This is the supply-side argument for export-led growth (Feder 1983). Likewise, exports matter because the sophistication of a country's export basket is a good predictor of its future growth (Hausmann, Hwang, and Rodrik 2007). A good example of this is given by the experience of fast-growing firms in several Asian countries, which moved up in the development ladder and consequently produced more sophisticated products by slowly accumulating productive capabilities. Exporting was a means of "testing" whether firms and sectors could compete in the global market place, by subjecting them to global competition. 
constrained. For this reason, exports play a very significant role because the evidence shows that countries, especially developing countries, need to maintain balance-of-payments equilibrium (BOPE) in the long run. Otherwise they run into crises. Indeed, the experience of many developing countries shows that, in the long run, no country can grow faster than the rate consistent with BOPE on current account, unless it can finance ever-growing deficits. There is a limit to the deficit-to-GDP ratio beyond which financial markets become nervous and a country is unable to borrow any more. Thus, countries that find themselves in balance-of-payments (BOP) problems must constrain growth, while the economy still has surplus capacity and surplus labor-indeed, there are not many developing countries that could not grow faster if they had more foreign exchange. This implies that exports not only have a direct effect on demand, but also an indirect effect by allowing all other components of demand to rise faster than otherwise would be the case. This helps us anticipate the result that the long-run rate of growth of an economy becomes attuned to the rate of growth of the dominant component of autonomous demand, which in an open economy is exports.

This paper contributes to the debates and literatures on ELG and the PRC's growth in several directions. First, we offer an alternative explanation (to the supply-side growth accounting) of the PRC's growth, one that allows us to consider explicitly the growth-enhancing effects of exports. In doing so, we offer a demand-side explanation of the PRC's growth in terms of the ELG hypothesis. By this we mean that the PRC's growth may well have been demand constrained, especially when it is below its productive potential-in which case there is excess capacity, supply constraints are not binding, and GDP growth is determined by the growth of demand. This possibility is acknowledged by Lin, Morgan, and Wan (2018b, pp. 238-42). We believe this hypothesis merits serious investigation.

Second, unlike the growth accounting approach, that relies on somewhat ad hoc assumptions about, for example, the future path of TFP growth (apart from the fact that its determinants are very unclear), this framework allows proper statistical testing.

Third, we make use of a framework that goes beyond regressions of output growth on export growth. There is a fairly robust literature that relies on the hypothesis put forward by Thirlwall (1979). The basis of this work is the contention that the relationship between output growth and exports needs to be analyzed in a BOPE framework, specifically considering not only the growth effect associated to exports but also the rise in imports brought about by fast exports and output growth. That is, exportled growth can be the pillar of a sustainable development process only if it relaxes the long-run constraint on growth imposed by the BOP. Under this view, a country's long-term growth performance will tend to converge toward that particular growth rate consistent with BOPE-the BOPE growth rate.

Fourth, the paper provides several empirical contributions to the literature on BOPE growth, as well as to our understanding of the PRC's growth. The most important is that we estimate a timevarying BOPE growth rate $\left(y_{B t}\right)$ for the PRC. To our knowledge, this is the first time that such an exercise has been carried out and this is somewhat surprising, since the hypothesis that the BOPE growth rate is fixed over time is a restrictive one. This is particularly so for an emerging economy like the PRC, which has undergone significant structural change in the past 4 decades. A second empirical contribution of this paper is that we rely on a Bayesian model averaging (BMA) approach to examine the factors driving the evolution of the BOPE growth rate in the PRC.

Building on this approach, this paper addresses the following questions: (i) to what extent can the BOPE growth rate explain the PRC's growth performance over the last 3 decades?; and (ii) what are the determinants of the PRC's BOPE growth rate? These issues, interesting in their own right from a theoretical viewpoint, are now very important for policy makers too as after the Great Financial Crisis 
the Chinese economy has entered a new phase of slower economic growth, which some see as structural and heralding the beginning of a 'New Normal' for growth in the PRC. ${ }^{4}$

The remainder of the paper is structured as follows. Section II derives the BOPE growth rate, discusses its interpretation, and provides a discussion of why the PRC's growth rate may indeed have been determined by its BOPE. Section III implements this methodology using annual data for 19812016. We find that the average value of the BOPE growth rate was $11 \%$ but, consistent with our hypothesis, it varied significantly during the estimation period. In section IV, we test how relevant (as an upper limit constraint) the BOPE growth rate has been to explain the PRC's actual growth rate. The evidence is consistent with the notion that the trajectory of the PRC's trend growth performance was determined by the dynamics of its BOPE growth rate. Section $\vee$ focuses on the investigation of robust determinants of the BOPE growth rate and of the income elasticity of imports via BMA analysis. Our findings indicate that the BOPE growth rate in the PRC is primarily influenced by specific components of aggregate demand. In particular, export growth has acted as the PRC's engine of growth and, at the same time, as a check on output growth via its direct and indirect effects on import growth and the BOP constraint. Finally, section VI concludes and discusses policy implications.

\section{THE BALANCE-OF-PAYMENTS EQUILIBRIUM GROWTH RATE MODEL}

The concept of the BOPE growth rate was put forward by Thirlwall (1979), and has given rise to a large theoretical and empirical literature (e.g., Guarini and Porcile 2016, Lanzafame 2014, Mayer 2017). Thirlwall's (1979) model is based on the idea that, in the long run, countries cannot run current account deficits, hence their current account needs to be in balance. Therefore, the term BOPE encapsulates the idea that a country's performance in external markets may ultimately constrain the growth of the economy to a rate below that which internal conditions would warrant.

To implement empirically the notion of BOPE, assume the following specifications for the export and import demand functions:

$$
\begin{aligned}
X_{t} & =\left(\frac{P_{d t}}{P_{f t}}\right)^{\eta} Z^{\varepsilon} \\
M_{t} & =\left(\frac{P_{d t}}{P_{f t}}\right)^{\theta} Y^{\pi}
\end{aligned}
$$

where $t$ indicates time, $X, M, Y$, and $Z$ are, respectively, the flows of exports, imports, domestic, and world income (in real terms), $P_{d}$ and $P_{f}$ are domestic and foreign prices (measured in a common currency), $\eta<0$ and $\theta>0$ are price elasticities, while $\varepsilon>0$ and $\pi>0$ are the income elasticities of exports and imports, respectively. The latter two play a crucial role in this model, as we shall see below.

4 As noted above, when using growth accounting approaches to identify the supply-side determinants of growth, i.e., the relative contributions of labor, capital, and total factor productivity (TFP), estimates vary widely depending on the particular dataset used. The optimists about the PRC's future generally find that the contribution of TFP growth to GDP growth is sizable. This implies that the PRC's high growth rates are likely to be sustained because they do not depend on a rapid rise in the capital-output ratio, which would imply a sharp decline in the rate of return to capital. The pessimists, on the other hand, tend to find that most of the PRC's growth can be attributed to capital deepening, which implies a substantial reduction of the return to capital, and hence is likely to limit potential growth going forward. 
In a growing economy, the long-run constraint imposed by the BOPE requires that exports and imports grow at the same rate, i.e., $x_{t}=m_{t}$. Figure 1 shows these two series. After peaking in the early-tomid 2000s, both series have trended downward in the PRC; in the case of exports, registering consecutive negative values in 2015 and 2016, and in the case of imports a negative growth rate in 2015.

Figure 1: Growth Rates of the Volumes of Exports and Imports

(a) Export volume

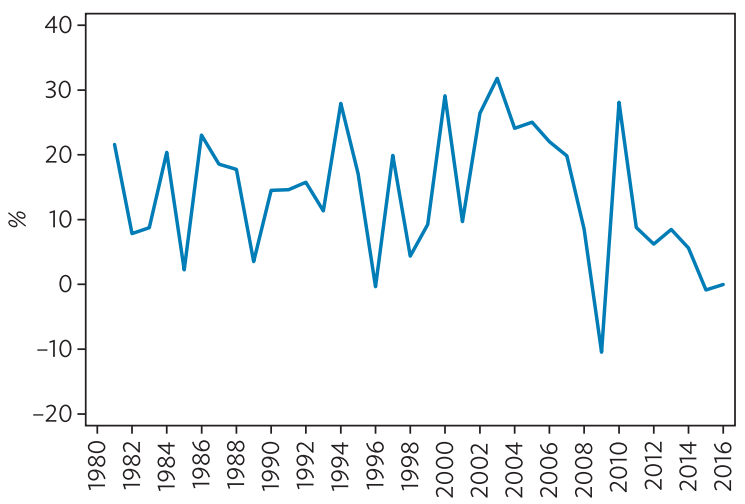

(b) Import volume

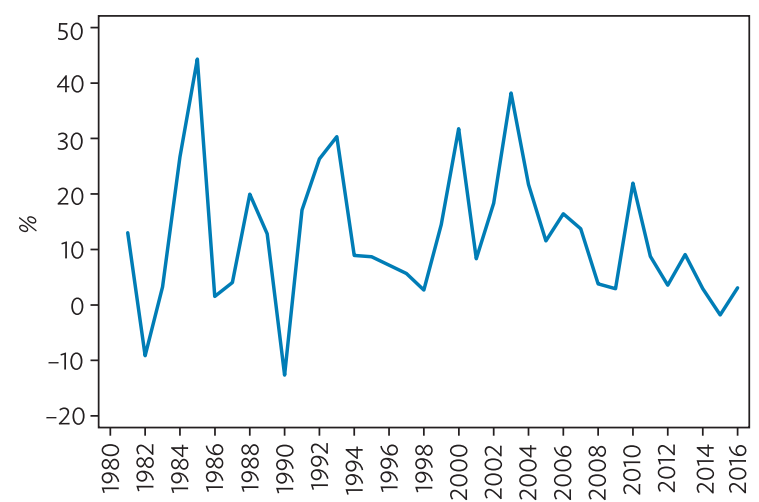

Source: Authors based on UNCTAD data.

Log-linearizing equations (1) and (2) and differentiating with respect to time, the equilibrium condition $x_{t}=m_{t}$ can be written as:

$$
\eta\left(p_{d t}-p_{f t}\right)+\varepsilon z_{t}=\theta\left(p_{d t}-p_{f t}\right)+\pi y_{t}
$$

where lowercase letters denote the growth rates of the relevant variables. If relative prices measured in a common currency do not change over the long run (i.e., $p_{d t}=p_{f t}$ ), equation (3) can be rearranged to give: ${ }^{5}$

$$
y_{B}=\frac{\varepsilon z_{t}}{\pi}
$$

The simple rule in equation (4) represents an upper limit to long-run growth, which becomes binding and, thus, constrains actual growth when a country's $y_{B}$ is lower than its potential growth rate. As such, the approach is labeled demand oriented because when $y_{B}$ is below potential growth, an increase in the growth of exports will increase the growth of output. This is not to say that the supply side is unimportant, since the emphasis on increasing the growth rate of exports inevitably involves supply-side measures. What is argued is that the direction of causation in equation (4) runs from the

5 This assumption need not be taken to be the same as the Law of one Price, i.e., that arbitrage ensures that the price of trade goods will be the same in the long run, hence all firms and countries face infinitely elastic demand curves, and the only factor that prevents countries to export more is supply constraints. This would imply that there are no BOP constraints, as small relative price changes will be sufficient to bring the current account into equilibrium. The Law of one Price is one of the most empirically refuted propositions in economics. Here, this assumption means that, in the long run, movements in relative prices are relatively small. The idea is simply that when exchange rate changes take place, domestic price movements tend to mirror those changes to keep real exchange rates relatively stable. 
right-hand side to the left-hand side, i.e., from the income elasticities, to the growth rate of output, via the BOP constraint on demand. These income elasticities are largely determined by a country's natural resource endowments and reflect the nonprice characteristics of exports and imports, such as quality, variety, reliability, speed of delivery or distribution network. All else constant, the better these characteristics, the higher the country's exports for a given growth rate of the world economy (i.e., the higher its $\varepsilon$ ) and the lower the import content for each of the components of aggregate demand (i.e., the lower its $\pi$ ).

Note that given that $\varepsilon z_{t}=x_{t}$, equation (4) can also be expressed as:

$$
y_{B}=\frac{x_{t}}{\pi}
$$

so that $y_{B}$ is given by the ratio of the growth rate of exports to the income elasticity of imports. To avoid the potential problems involved in the estimation of the export function, relating in particular to the selection of an appropriate proxy for $z_{t}$, the empirical relevance of the BOPE growth model is usually investigated by relying on the simple rule expressed in equation (5). The accuracy of equation (5) approximating actual growth depends crucially on the estimate of the income elasticity of demand for imports $(\hat{\pi})$, which can be retrieved from a standard aggregate import function, such as the loglinear specification (equation [2] log linearized):

$$
\log M_{t}=\gamma+\theta\left(\log P_{d t}-\log P_{f t}\right)+\pi \log Y_{t}+\mu_{t}
$$

As the relationship in equation (5) is concerned with long-run growth and the variables involved often display nonstationary behavior, equation (6) is typically estimated via cointegration methods (e.g., Bairam 1993, Alonso 1999, Bagnai 2010).

Equation (5) offers an alternative view to the growth accounting (supply-side) explanation of growth in general, and of the PRC's fast growth in particular. ${ }^{6}$ The thrust of the argument is that economies typically expand at a slower pace than their potential growth rate, so that there is excess capacity, supply constraints are not binding and, thus, their growth rate is determined by the growth of demand. In this framework, therefore, growth rates across countries must differ because the growth of demand differs among them. As in the case of several East Asian countries in the past, the PRC's growth performance was boosted by the development of its export capabilities (in particular manufactures) to and beyond the threshold associated to the cost of full-employment imports (i.e., the value of imports that would occur if resources were fully utilized). In other words, the growth of exports relaxed the BOP constraint imposed by the import requirements of rapid growth. In more recent times, this process has led the PRC to run significant current account surpluses-a typical

6 The relevance of nonprice competitiveness in the Asian context appears to be supported by the statistical analysis of Ang, Madsen, and Robertson (2015). These authors show that the spectacular productivity and export growth rates experienced by the Asian economies in their analysis (India; Japan; the PRC; the Republic of Korea; Singapore; and Taipei,China) during 1953-2010, were driven by innovation, in particular of diversification (new product variety), an outcome of research and development in the intermediate goods producing sector. The coefficient of the (trade-weighted) income variable (proxy for nonprice competitiveness) is highly significant and high (elasticity), about 2. On the other hand, price competitiveness (measured by the price elasticities) was not a quantitatively important determinant of export. They also find that innovation competitiveness has been less influential for export growth for the PRC and India. These two countries' export booms were more based on imitation and process innovation than on product innovation. 
indication of a high BOPE growth rate. This was also the case of countries such as Japan, Germany, Switzerland and the oil-producing economies of the Middle East, in the past.

This discussion naturally raises a number of questions: what is the value of the growth rate consistent with current account equilibrium in the PRC?; has it changed over time?; what are the determinants of the PRC's BOPE growth rate?; can growth in a country like the PRC, which has received significant inflows of foreign direct investment (FDI), be explained by the dynamics of its BOPE growth rate? And if that is the case, what are the implications? This paper provides answers to these questions. Our approach starts from recognizing that, if the BOPE growth rate is found to be a good approximation of a country's long-run growth rate, the implication is that relative price changes and capital flows do not matter in the long run. Short-term deviations of the actual growth rate from the BOPE growth rate are, of course, possible-and will give rise to current account improvements or deteriorations, associated to corresponding capital flows. These deviations, however, cannot persist in the long run, as deficits will sooner or later be corrected via a slowdown in growth, while current account surpluses will lead to faster growth, at least until the economy's growth becomes constrained by its productive capacity. The latter case appears to fit well the PRC's experience, at least from the early 2000s, when the country has enjoyed a healthy current account surplus. Empirically, the implication of this argument is that the BOPE growth rate can be expected to approximate an economy's long-run (trend) growth rate, rather than its actual growth rate. More specifically, the BOPE growth rate can be expected to cause the trend growth rate. Thus, our empirical work in this paper focuses on the relationship and the direction of causality between the PRC's BOPE growth rate and its trend growth rate.

Capital flows can, of course, not only allow short-term deviations of growth from the BOPE growth rate, but also affect the latter-if they influence a country's export performance and/or its income elasticity of imports. This is particularly the case of FDI, whose most important contribution to the PRC's development has probably not been physical capital (since the country enjoys high saving and investment rates), but access to advanced technologies and management (Zhang 2015). Of enormous importance has also been entry into global markets, as foreign investors integrate their operations in the PRC into their global supply chains. Therefore, these flows have contributed to the country's development and may have helped relax the BOP constraint in the sense of increasing the PRC's BOPE growth rate. Whether that was really the case is an empirical question, which we address in the context of our investigation of the determinants of the PRC's BOPE growth rate.

\section{ESTIMATION RESULTS OF THE PEOPLE'S REPUBLIC OF CHINA'S TIME-VARYING BALANCE-OF-PAYMENTS EQUILIBRIUM GROWTH RATE}

Empirical studies in the literature consider the BOPE growth rate as constant and, typically, compute its value as the ratio of average export growth to the (point estimate) income elasticity of imports, over a certain time span. Some of the most recent point estimates of the PRC's $y_{B}$ are provided by Hussain (2004) for 1976-1989 and Jeon (2009) for 1979-2002. Hussain (2004) estimated the PRC's $y_{B}$ rate at $6.36 \%$-lower than, but not statistically different from, the average actual growth rate of $8.2 \%$. Jeon (2009) found that the Chinese economy grew, on average, as fast as its $y_{B}$ over 1979-2002-the average actual growth rate (9.25\%) and the estimated $y_{B}$ were found to be not statistically different.

However, unless $x_{t}$ or $z_{t}$ are constant, a simple look at equations (4) and (5) shows that, even not considering short-term variation, the value of $y_{B}$ will change over time because of changes in trend growth rate of exports. More importantly, the long-run value of $y_{B}$ will also be time varying if the income elasticity of imports is not a fixed parameter but, in fact, itself subject to changes over time. 
Since $\pi$ captures nonprice competitiveness and, more generally, an economy's structural characteristics, its value is very likely to be time varying, particularly for economies that have undergone and/or are still undergoing substantial structural change, such as the PRC's.

Based on this, this section provides time-varying estimates of the PRC's $\pi_{t}$ and BOPE growth rate, relying on Kalman filtering techniques. Models with time-varying parameters can accommodate and account for changes in an economy's structural features, which may have an impact on trade elasticities. Since the potential nonstationarity of the variables in the log-level version of the import function in (6) makes the use of the Kalman filter impractical in this case, we rely on the growth rate version of the import function in (2). The latter is specified in a state-space model with time-varying parameters and estimated relying on the Kalman filter recursive algorithm, which is commonly used to estimate time-varying coefficients. ${ }^{7}$ A state-space model consists of two sets of equations, called measurement and state. The Kalman filtering approach provides optimal estimates for state variables based on the information from these two sources. Hence, our model consists of the following system of equations, with the imports growth relation in (7) being the measurement equation and (8)-(9) the two state equations:

$$
\begin{gathered}
m_{t}^{T}=\theta_{t} r p_{t}+\pi_{t} y_{t}^{T}+u_{t} \\
\theta_{t}=\theta_{t-1}+v_{t} \\
\pi_{t}=\pi_{t-1}+v_{t}
\end{gathered}
$$

where lowercase letters denote growth rates, $r p_{t}=\left(p_{d t}-p_{f t}\right)$ and the terms $v_{t}$ and $v_{t}$ are independent normally distributed errors, with zero mean and constant variance. The parameters $\theta_{t}$ and $\pi_{t}$ are, respectively, the time-varying price and income elasticities of imports. Since the BOPE growth rate is held to be a long-term constraint on growth, we need to purge the estimated $\pi_{t}$ and, thus, the relationship between the growth rates of imports and output from short-run fluctuations. Thus, to estimate equation (7), we rely on $m_{t}^{T}$ and $y_{t}^{T}$ which denote the trend growth rates of imports and output, respectively. ${ }^{8}$ Note also that, to capture possible level breaks or trend patterns, we impose a unit root in the state equations-this is a standard procedure in the literature on state-space modeling (e.g., Harvey 1989).

To obtain time series for the state variables we apply the Kalman smoothing procedure, which uses all the information in the sample to provide smoothed state estimates. ${ }^{9}$ This procedure differs from the Kalman filter in the construction of the state series, as the latter technique uses only the information available up to the beginning of the estimation period. Smoothed series tend to produce more gradual changes than filtered ones and, as discussed by Sims (2001), they provide more precise estimates of the actual time variation in the data.

7 A wide variety of time series models can be written and estimated as special cases of a state-space specification. Extensive examples of applications of state-space models can be found in Harvey (1989).

8 The two trend growth rates are obtained via the frequency domain filter developed by Corbae, Ouliaris, and Phillips (2002) and Corbae and Ouliaris (2006). The Corbae-Ouliaris filter grants several advantages with respect to the available alternatives, such as the commonly used Hodrick-Prescott filter or the Baxter-King filter: It can handle both stochastic and deterministic trends, it avoids the end-point issue estimating end-points directly, it does not require the investigator to set any parameters except the business cycle range.

9 Suppose that we observe the sequence of data up to time period $t$ : The process of using all this information to form expectations at any time period up to $t$ is known as smoothing. 
The analysis is carried out using annual data for 1981-2016. We make extensive use of the recently constructed dataset by Chang et al. (2016) which, to our knowledge, is the most complete and consistent source of macroeconomic data on the PRC to date.

Our estimate of the time-varying BOP-constrained growth rate $\left(y_{B t}\right)$ is constructed as follows:

$$
y_{B t}=\frac{x_{t}^{T}}{\hat{\pi}_{t}}
$$

where $\hat{\pi}_{t}$ is the estimate of the income elasticity of imports obtained from the state-space model in (7)-(9) and $x_{t}^{T}$ is the trend growth rate of exports.

Figure 2 shows numerator and denominator of $y_{B t}$ in equation (11), while Figure 3 shows the estimates of the BOPE growth rate, together with actual $\left(y_{t}\right)$ and trend $\left(y_{t}^{T}\right)$ output growth rates. Figure 2 indicates that, indeed, both components of the BOPE growth rate varied significantly during the estimation period. Recall that the income elasticity of imports encapsulates the nonprice characteristics of the PRC's imports, or of world exports to the PRC. It oscillated between 1 and 1.5 between 1981 and the late 1990s, when it started increasing and reached 2.7 in the early 2000 s. ${ }^{10}$ This is in line with the evidence indicating that, as the PRC's income increased, its imports became progressively more sophisticated. These imports included intermediate goods (e.g., chemicals) and machinery, as well as more sophisticated consumer products-a reflection of the PRC's structural transformation. Then, and somewhat surprisingly, the elasticity started declining rapidly to below 1 in 2010 and to about 0.5 and even less, in recent years."

The trend growth rate of exports, on the other hand, oscillated around $15 \%$ per annum until about the year 2000. Given that $\varepsilon z_{t}=x_{t}$, and that world income growth $\left(z_{t}\right)$ was much lower, we can infer that the income elasticity of the PRC's exports $(\varepsilon)$, a proxy for the nonprice characteristics of the PRC's exports, increased very fast and reached very high values. This had to be the consequence of the transformation (diversification and upgrading) of the PRC's export structure (see Felipe et al. 2013). The PRC's export growth increased to 25\% in the mid-2000s, and then declined fast to well below 5\% after the financial crisis. ${ }^{12}$

10 The point estimates of the income elasticity of imports in Hong et al. (2016, Tables 1, 2) vary from 1.5 to 2 , depending on the specification and sample. Hussain (2004, Table 14.4) gives an income elasticity of imports of 1.76.

11 We also estimated the income elasticity of imports from equation (6) using rolling regressions (with a window of 15 years) and obtained very similar values. The elasticity also declines rapidly after 2000 in these regressions.

12 As noted earlier (Figure 1), the trend growth rates of both exports and imports peaked in the early 2000 s. Since then both series have been on a downward trend. 
Figure 2: Estimated Income Elasticity of Imports and Trend Growth Rate of Exports of the People's Republic of China, 1981-2016

(a) Estimated income elasticity of imports

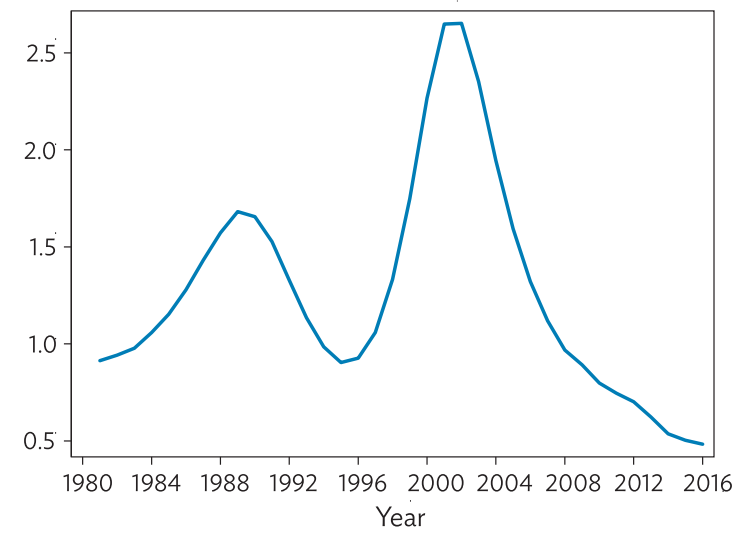

(b) Trend growth rate of exports

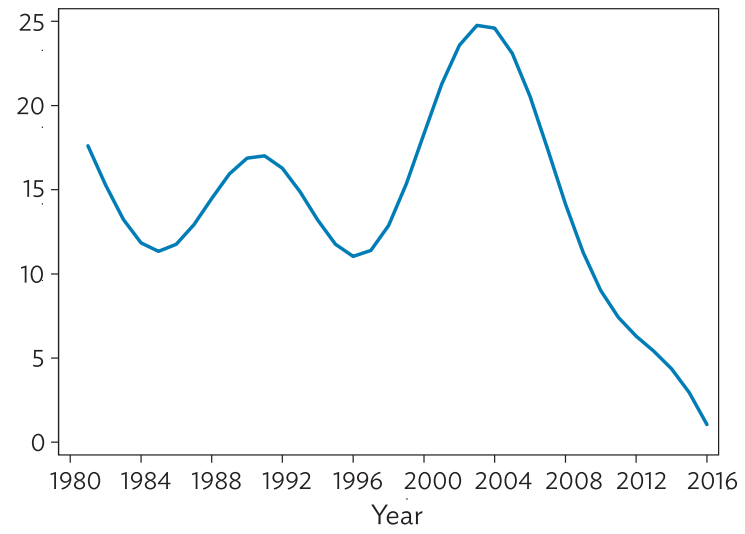

Source: Authors

Figure 3: Actual, Trend, and Balance-of-Payments Equilibrium Growth Rates of the People's Republic of China, 1981-2016

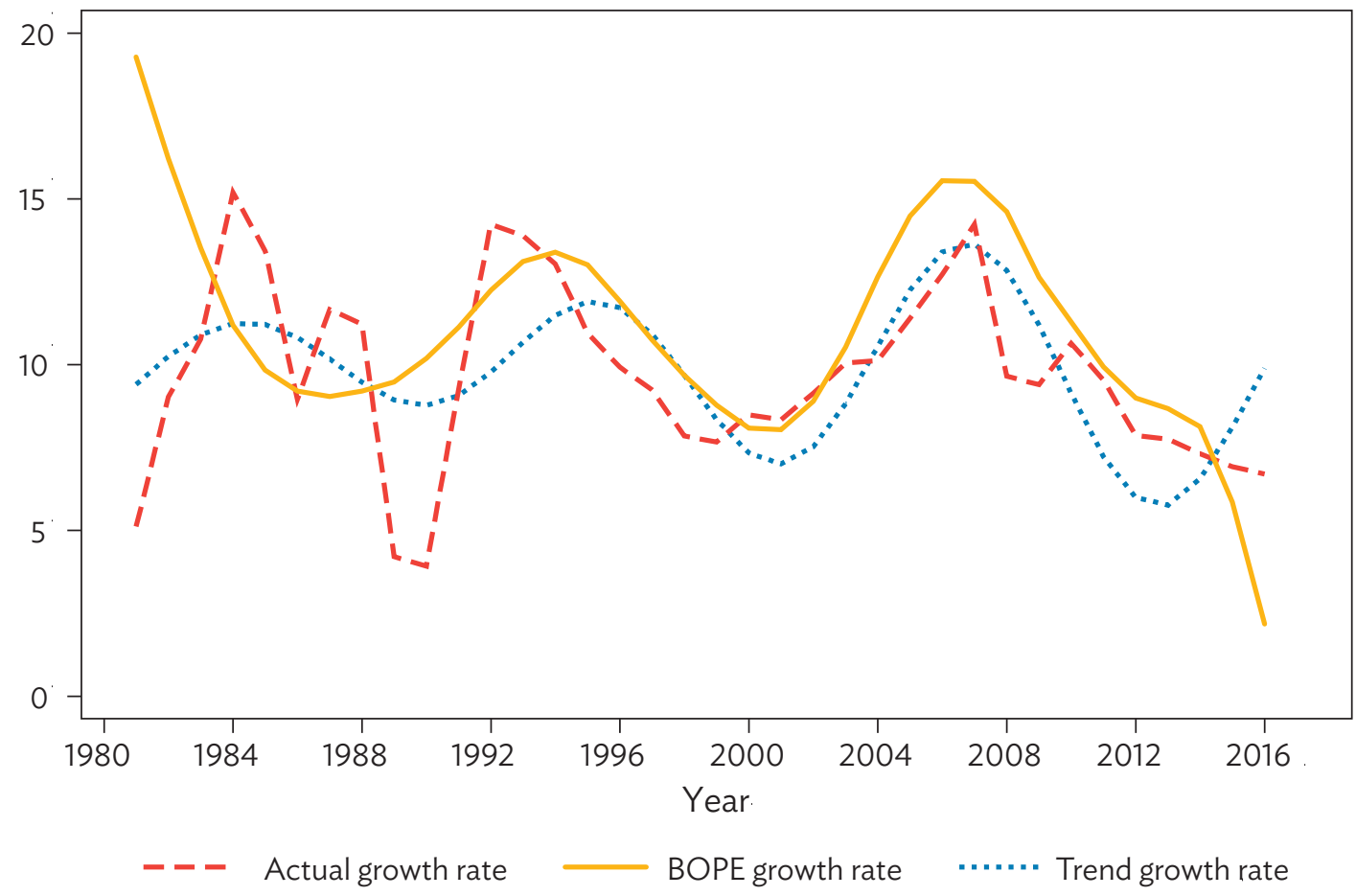

BOPE = balance-of-payments equilibrium . Source: Authors. 
The average value of the PRC's estimated $y_{B t}$, the long-run growth rate that the PRC could achieve without running into BOP problems for 1981-2016, is a very high $11 \%$. The available estimates in the literature (e.g., Hussain 2004) indicate that very few countries have enjoyed similar values for the BOPE growth rate. However, Figure 3 shows significant variation over time. Before the Great Financial Crisis of 2007 (and excluding the 1981-1982 years), the PRC's $y_{B t}$ remained above 9\% for the whole period considered except for 1999-2002 (when it was, nonetheless, above 8\%), reaching a peak value of $15.5 \%$ in 2006-2007, the result of a very high growth rate of exports and an already declining import elasticity. This BOPE growth rate was above the actual growth rate. This is a reflection of the accumulation of payment surpluses. The interpretation in terms of BOPE growth model is that the PRC did not grow faster than it did because of an ultimate capacity ceiling. In this sense, the supply side (factors of production) constrained, rather than determined, the PRC's growth. The PRC, nevertheless, grew faster than most other countries in the world because demand was unconstrained and induced its own supply of factors of production. From 2007 onwards, the BOPE growth rate has declined to about $8 \%$ in 2014 and it is estimated to be $5.9 \%$ in 2015. Although the growth rate of exports declined very fast after the financial crisis, to about $1 \%-2 \%$ in recent years (Figure 1), the significant decline in the PRC's $y_{B t}$ in recent years could also be due (at least partly) to estimation problems of the income elasticity of imports-as discussed below, this is particularly so for the 2016 estimate. Therefore, we consider our 2015 estimate of 5.9\% as the most reliable current estimate of the PRC's $y_{B t}$-meaning that the country cannot grow faster than this rate without eventually running into BOP problems.

Inspection of Figure 3 indicates that, with a few exceptions, $y_{B t}$ is always above the trend growth rate $\left(y_{t}^{T}\right)$, particularly from the early 1990s onwards. Moreover, there is a pretty clear positive correlation between the two series, which appear to move together for most of the period under analysis. Similar comments apply to the relationship between $y_{B t}$ and the actual growth rate $\left(y_{t}\right)$ although, as expected, the deviations between these two series are larger, and the correlation is lower, than between $y_{B t}$ and $y_{t}^{T}$, particularly in the 1980s. This evidence is in line with Thirlwall's hypothesis that the BOPE growth rate represents a long-term limit to actual growth, which implies a higher correlation with the trend growth rate than with the actual growth rate.

Before moving on to the formal tests of the significance of these correlations, some caveats about the estimates in Figure 3 need to be mentioned. First, the poor performance of the BOPE model in the 1980s may be the result of the fact that the PRC's transition toward a market economy was still in its early stages, so the relationship that equation (5) (BOPE approach) may not capture properly the country's growth dynamics during that period. Second, like other filtering techniques, the Kalman smoother does not perform so well for beginning-of-period estimates-as no information is available for earlier years, the $y_{B t}$ estimate for 1981 is based solely on data for the following years, which explains (at least partly) the very high value obtained. A similar point can be made for estimates of the last years in the sample, particularly for 2016, when the estimate declines to $2.2 \%$. Third, estimates for the years 1989-1991 are problematic, as the PRC's economy was affected by a substantial negative shock, including trade sanctions. In addition, the economic reforms were essentially put on hold. As a result, the PRC's GDP growth rate fell from $11.2 \%$ in 1988 to $4.2 \%$ in 1989, and declined further to $3.9 \%$ in 1990. In 1991, several economic sanctions were lifted, economic reforms were resumed and output growth increased to $9.3 \%$. To avoid undue influence of this shock on the results, in what follows we exclude the years 1989-1991 from the econometric analysis. 


\section{HOW RELEVANT IS THE BALANCE-OF-PAYMENTS EQUILIBRIUM GROWTH RATE FOR THE PEOPLE'S REPUBLIC OF CHINA?}

As argued earlier, one advantage of the BOPE growth approach over growth accounting is that the former's predictions can be properly tested - this is what we do in this section, proceeding in two stages:

(i) First, for the BOPE growth rate to represent an anchor for long-run growth, it must be the case that, on average, the PRC's actual growth rate in the period under analysis was not significantly different from its BOPE growth rate; or, equivalently, that deviations of actual growth from $y_{B t}$ were temporary. We carry out formal tests of both hypotheses.

(ii) Second, the approach indicates that in the adjustment mechanism bringing in line the actual and BOPE growth rates in the long run, the direction of causality runs from $y_{B t}$ to the actual growth rate. We investigate this hypothesis by relying on Granger-causality tests.

\section{A. Was the People's Republic of China's Growth Significantly Different from Its Balance-of- Payments Equilibrium Growth Rate?}

Theory indicates that actual growth will not deviate from the BOPE growth rate in the long run or, equivalently, that $y_{t}-y_{B t}=y$ diff $_{t}=0$. This is consistent with three testable hypotheses:

(i) $y$ diff $f_{t}$ is a stationary, mean-reverting process. This is a necessary, but not sufficient, condition that we test relying on standard unit root tests;

(ii) $y$ diff $_{t}$ is a zero-mean process. We test this second hypothesis by modeling $y \operatorname{diff}_{t}$ as an autoregressive (AR) process, i.e., ydiff $t_{t}=\theta+\sum_{i=1}^{l} \lambda_{i} y_{\text {diff }}+v_{t-i}$. For the theory to be supported by the data, the null hypothesis $H_{0}: \theta=0$ should not be rejected at the usual significance levels.

(iii) $y_{B t}$ does not differ significantly from the trend growth rate $y_{t}^{T}$, i.e., $y_{B t}=y_{t}^{T}$. We test this hypothesis by relying on the following specification $y_{B t}=\alpha+\beta y_{t}^{T}+u_{t}$, where the null hypothesis is $H_{0}:(\alpha, \beta)=(0,1)$, with the coefficient of $y_{t}^{T}$ statistically significant.

Test results are reported in Table 1:

(a) Hypothesis I: all unit root test results indicate that ydiff is a stationary process. The Dicky-Fuller generalized least squares (Elliott, Rothenberg, and Stock 1996) and Zivot and Andrews (1992) tests strongly reject the null of a unit root, while the Kwiatkowski, Phillips, Schmidt, and Shin (1992) test does not reject the null of stationarity. Moreover, the ZA test, which allows for an endogenously selected structural break, indicates that the latter is (as expected) present in 1989.

(b) Hypothesis II: we find evidence that supports the long-run equivalence between the actual and BOPE growth rates in the PRC: independently of the lag order, the three AR specifications considered in Table 1 return estimates of the constant that are not 
significantly different from zero. The upshot of this analysis, therefore, is that ydiff is a zero mean stationary process: in other words, actual growth in the PRC tends to be equal to the BOPE growth rate on average, as short-term divergences between the two rates do not last. Indeed, the calculated half-lives (between about 7 months and 1 year, depending on the AR specification) indicate that deviations from the long-run equilibrium are not very persistent either.

(c) Hypothesis III: The test results reject the hypothesis that $y_{B t}$ does not differ significantly from $y_{t}^{T}$. Indeed, although the estimated constant term is not significant and the null $H_{0}: \beta=1$ is not rejected, the joint hypothesis $H_{0}:(\alpha, \beta)=(0,1)$ is marginally rejected by the data with a $\mathrm{p}$-value of 0.044 . However, as it turns out, this outcome is entirely due to the less reliable beginning-of-period estimate for $y_{B t}$ : if the year 1981 is excluded from the sample, the F-statistic on the joint null is 2.35 , with a $p$-value of 0.114 . For completeness, we also run the test for the actual growth rate $y_{t}$. As expected, in this case we reject the null hypothesis, as the estimated $\hat{\beta}$ is not significantly different from zero. This is in line with the proposition that the BOPE growth rate should be thought of as a long-term growth rate, from which economies can deviate in the short run.

Table 1: Tests of Hypotheses I, II, and III

\begin{tabular}{|c|c|c|c|}
\hline & \multicolumn{3}{|c|}{ Hypothesis I: Unit root tests on $y$ diff $f_{t}$} \\
\hline & DF-GLS & KPSS & ZA \\
\hline & $-3.109^{* *}$ & 0.124 & $-5.086^{*}$ \\
\hline & \multicolumn{3}{|c|}{$\begin{array}{l}\text { Hypothesis II: Test based on } \\
\text { ff } f_{t}=\theta+\sum_{i=1}^{l} \lambda_{i} y \text { diff }_{t-i}+v_{i}\end{array}$} \\
\hline$y \operatorname{diff}_{t-1}$ & $0.501^{* *}$ & $0.773^{* *}$ & $0.713^{* *}$ \\
\hline $\operatorname{ydiff}_{t-2}$ & - & $-0.309^{\wedge}$ & -0.329 \\
\hline$y \operatorname{diff}_{t-3}$ & - & - & -0.066 \\
\hline Constant & 0.044 & -0.226 & -0.372 \\
\hline$R$-squared & 0.428 & 0.382 & 0.389 \\
\hline \multirow[t]{2}{*}{ Half-life } & 1.004 & 0.902 & 0.606 \\
\hline & \multicolumn{3}{|c|}{ Hypothesis III: Test based on $y_{B t}=\alpha+\beta y_{t}^{T}+u_{t}$} \\
\hline$y_{t}^{T}$ & $0.921^{* *}$ & - & \\
\hline$y_{t}$ & - & 0.457 & \\
\hline Constant & 2.028 & $6.504^{\wedge}$ & \\
\hline$R$-squared & 0.332 & 0.115 & \\
\hline F-statistic on $H_{0}: \beta=1$ & 0.53 & 2.61 & \\
\hline F-statistic on $H_{0}:(\alpha, \beta)=(0,1)$ & 3.46 & 1.90 & \\
\hline
\end{tabular}

DF-GLS = Dickey-Fully generalized least squares; KPSS = Kwiatkowski, Phillips, Schmidt, and Shin; ZA = Zivot and Andrews.

Notes: ${ }^{* *},{ }^{*}$, and ${ }^{\wedge}$ indicate, respectively, significant at the 1\%,5\%, and $10 \%$ level; Lag-selection for the unit root tests performed with a general-

to-simple procedure, setting the maximum number of lags to 3 ; Half-life calculated as $\operatorname{Ln}(0.5) / \operatorname{Ln}\left(\sum_{i=1}^{l} \lambda_{i}\right)$ and expressed in years.

Source: Authors. 
Summing up, we find qualified support for the hypothesis that the PRC's long-run growth performance reflects very closely the dynamics of its BOPE growth rate. We conclude that the demand-side explanation of the PRC's long-run growth performance fits the data well, both for its fastgrowing years and for the recent growth slowdown phase, when declining actual growth has been mirrored by a similarly falling BOPE growth rate. In the next section, we further investigate whether these similarities have been driven by the dynamics of the PRC's $y_{B t}$.

\section{B. Does the Balance-of-Payments Equilibrium Growth Rate Cause the Actual Growth Rate? A Vector Autoregression Analysis}

The tests carried out in the previous section allowed us to ascertain that the PRC's actual growth is correlated with $y_{B t}$, but they cannot be relied upon to investigate the direction of causality. It could be argued that this correlation may (at least partly) reflect causation running from actual growth to $y_{B t}$. This is because, as illustrated by the cumulative causation (export-led) growth models (e.g., Dixon and Thirlwall 1975), if productivity growth is endogenous with respect to $y_{t}$, faster output growth can boost export growth and, thus, raise the BOPE growth rate. Similarly, the pace of structural change can be partly dependent on $y_{t}$ and, if that is the case, both the income elasticity of imports (IEol) and the BOPE growth rate will also be endogenous with respect to actual growth. Investigating the direction of causality is, thus, crucial to answer the question of whether the PRC's growth performance may have been driven by demand-side factors and, in particular, by its export growth.

To examine these issues, we rely on Granger-causality methods using a vector autoregression (VAR) setup, which allows for richer dynamics, and takes account of the potential endogeneity of $y_{B t}$. Following Granger (1969), a variable $Y_{t}$ is said to 'Granger-cause' another variable $X_{t}$ when past values of $Y_{t}$ significantly reduce the predictive error variance of $X_{t}$. Thus, in a regression of $X_{t}$ on its own lags and lags of $Y_{t}$, the null hypothesis that $Y_{t}$ does not Granger-cause $X_{t}$ (in our notation, $Y_{t} \nrightarrow X_{t}$ ) cannot be rejected if lags of $Y_{t}$ are found to be jointly statistically insignificant. To perform Grangercausality tests, we estimate the following reduced-form VAR model:

$$
Y_{t}=\alpha+A(L) Y_{t}+u_{t}
$$

where $A(L)$ is a matrix polynomial in lag operator $L, \operatorname{var}\left(u_{t}\right)=\sum$, and $Y_{t}$ is either a two-variable or a three-variable vector. Specifically, we first foçus directly on the relationship between trend growth and the BOPE growth rate, so that $Y_{t}=\left(y_{t}^{T}, y_{B t}\right)$. Next, we use the definition of the BOPE growth rate to examine individually the relationships between trend output growth, the trend growth rate of exports and the estimated income elasticity of imports, i.e., $Y_{t}=\left(y_{t}^{T}, x_{t}^{T}, \hat{\pi}_{t}\right)$. This allows us to investigate whether the correlation between $y_{t}^{T}$ and $y_{B t}$ may be driven solely by the export growth series, thus undermining the argument that is the basis of the BOPE growth approach.

It is important to note that, since both $y_{B t}$ and $\hat{\pi}_{t}$ are nonobservable and, therefore have been estimated (with an associated standard error), their inclusion in our VAR model increases the standard deviation of the estimates and lowers the $t$-statistics. That is, the presence of an additional unmeasurable error term due to the inclusion of $y_{B t}$ and $\hat{\pi}_{t}$ decreases the significance of our estimates. Thus, the results from the VAR-based analysis in this section have to be taken with some caution. 
Table 2 reports the Granger-causality tests for the relationship between $y_{B t}$ and $y_{t}^{T} .^{13}$ The first two rows of the table report the results for the direction of causality between $y_{B t}$ and $y_{t}^{T}$ : the null $y_{B t} A y_{t}^{T}$ is strongly rejected by the data, while we find only weak evidence supporting the hypothesis of causality running also from $y_{t}^{T}$ to $y_{B t}$.

Table 2: Granger-Causality Tests for the Relationship between $y_{B t}$ and $y_{t}^{T}$

\begin{tabular}{|c|c|}
\hline & F-statistic \\
\hline$y_{B t} \nrightarrow \neg y_{t}^{T}$ & $5.85^{* *}$ \\
\hline$y_{t}^{T} \nrightarrow A y_{B t}$ & $2.51^{\wedge}$ \\
\hline$x_{t}^{T} \not \neg y_{t}^{T}$ & $7.00^{* *}$ \\
\hline$y_{t}^{T} \not \neg x_{t}^{T}$ & $7.22^{* *}$ \\
\hline$\hat{\pi}_{t} \nrightarrow \neg y_{t}^{T}$ & $4.52^{*}$ \\
\hline$y_{t}^{T} \nrightarrow \neg \hat{\pi}_{t}$ & $2.97^{\wedge}$ \\
\hline$x_{t}^{T} \not \neg \hat{\pi}_{t}$ & $20.93^{* *}$ \\
\hline$\hat{\pi}_{t} \nrightarrow x_{t}^{T}$ & 2.13 \\
\hline
\end{tabular}

Notes: ${ }^{* *},{ }^{*}$, and ${ }^{\wedge}$ indicate, respectively, significant at the 1\%, 5\%, and 10\% level. ' $\rightarrow$ ' indicates 'does not Granger-cause'.

Source: Authors.

The remaining rows of Table 2 provide the F-statistics for the Granger-causality tests relating to the various channels potentially linking $y_{B t}$ to $y_{t}^{T}$. We find significant evidence of bidirectional causality between trend exports and output growth, in line with the export-led hypothesis for the PRC. However, while the null hypothesis $y_{t}^{T} \neg \hat{\pi}_{t}$ is rejected only at the $10 \%$ level, we also find significant evidence that the income elasticity of imports Granger-causes the trend growth rate $y_{t}^{T}$. Such an outcome brings additional support for the hypothesis that ELG in the PRC cannot be understood properly without considering its long-term BOP dynamics and, therefore, it reinforces the empirical support for the BOPE approach uncovered in the previous section. Finally, we find very strong evidence that $x_{t}^{T}$ Grangercauses the IEol, while the opposite is not true. As further clarified in the next section, since exports are one of the most import-intensive components of aggregate demand, this outcome is hardly surprising.

To complete the analysis, we trace out the effects on $y_{t}^{T}$ of shocks to $y_{B t}$ and to $x_{t}^{T}$ and $\hat{\pi}_{t}$, considering impulse response functions (IRFs) over a 10-year time span. ${ }^{14}$ Figure 4 shows that, as expected, the response of $y_{t}^{T}$ to a shock in the BOPE growth rate is positive up to year 5 , while it becomes not significant afterwards. Figure 5 shows that the response of trend output growth to a shock in $x_{t}^{T}$ is (somewhat surprisingly) initially negative, but it takes on the expected significantly positive

13 Based on the Likelihood Ratio test, as well as the Akaike and Information Criterion and the Schwarz Bayesian Information Criterion, the selected number of lags for all VAR models is 3.

14 Due to the aforementioned concerns about the lack of significance of our estimates, we use a conservative $10 \%$ confidence interval for the IRF. 
sign from year 6 onwards. Meanwhile, the response of $y_{t}^{T}$ to a shock in $\hat{\pi}_{t}$ is initially not significant, but it becomes significantly negative (again, as expected) from year 7 onwards. ${ }^{15}$

Figure 4: Estimated Impulse Response Function to a One Standard Deviation Shock in $y_{B t}$

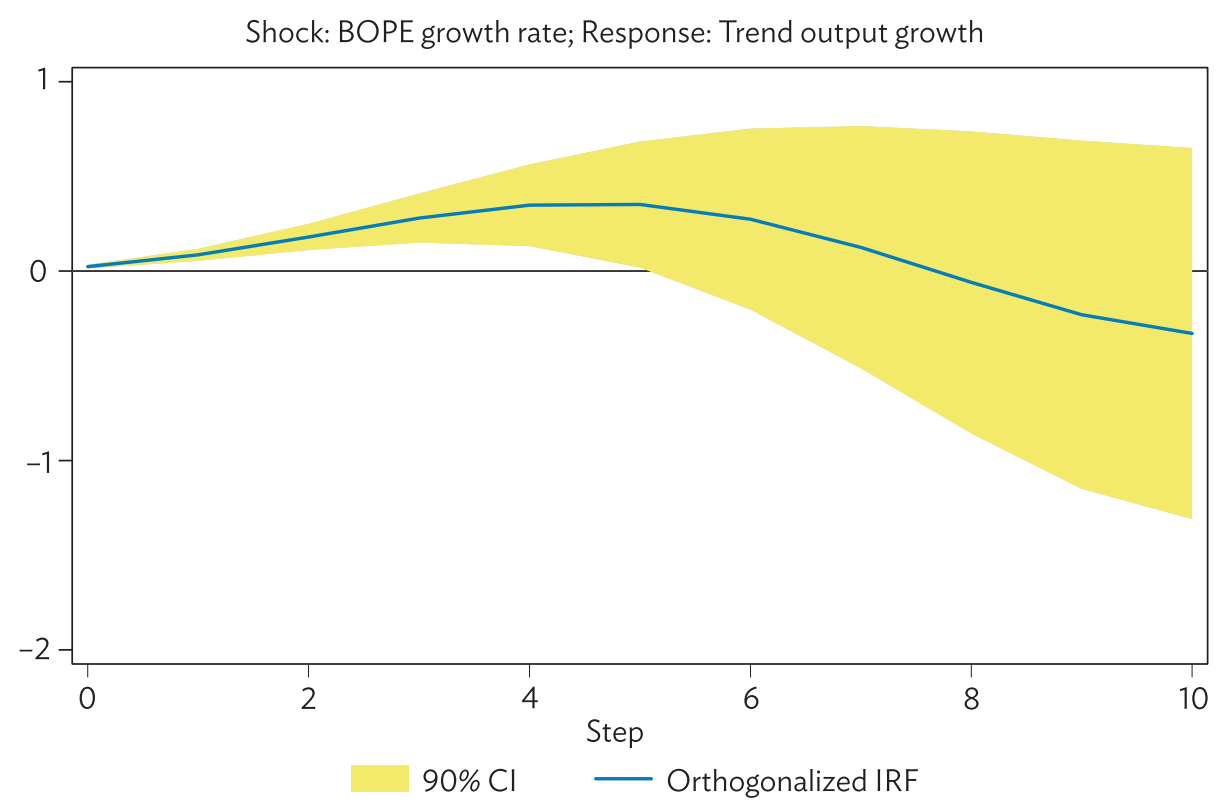

$\mathrm{BOPE}=$ balance-of-payments equilibrium, $\mathrm{Cl}=$ confidence interval, $\mathrm{IRF}=$ impulse response function . Source: Authors.

15 We also carried out the Granger-causality analysis, and estimated the IRFs, for the actual growth rate: as expected, the results provide weaker evidence of a significant causal relationship between the BOPE growth rate (or its components) and $y_{t}$. To save space, these results are not included in the paper-they are available from the authors upon request. 
Figure 5: Estimated Impulse Response Functions to a One Standard Deviation Shock in $x_{t}^{T}$ and $\hat{\pi}_{t}$

Shock: Trend exports growth; Response: Trend output growth
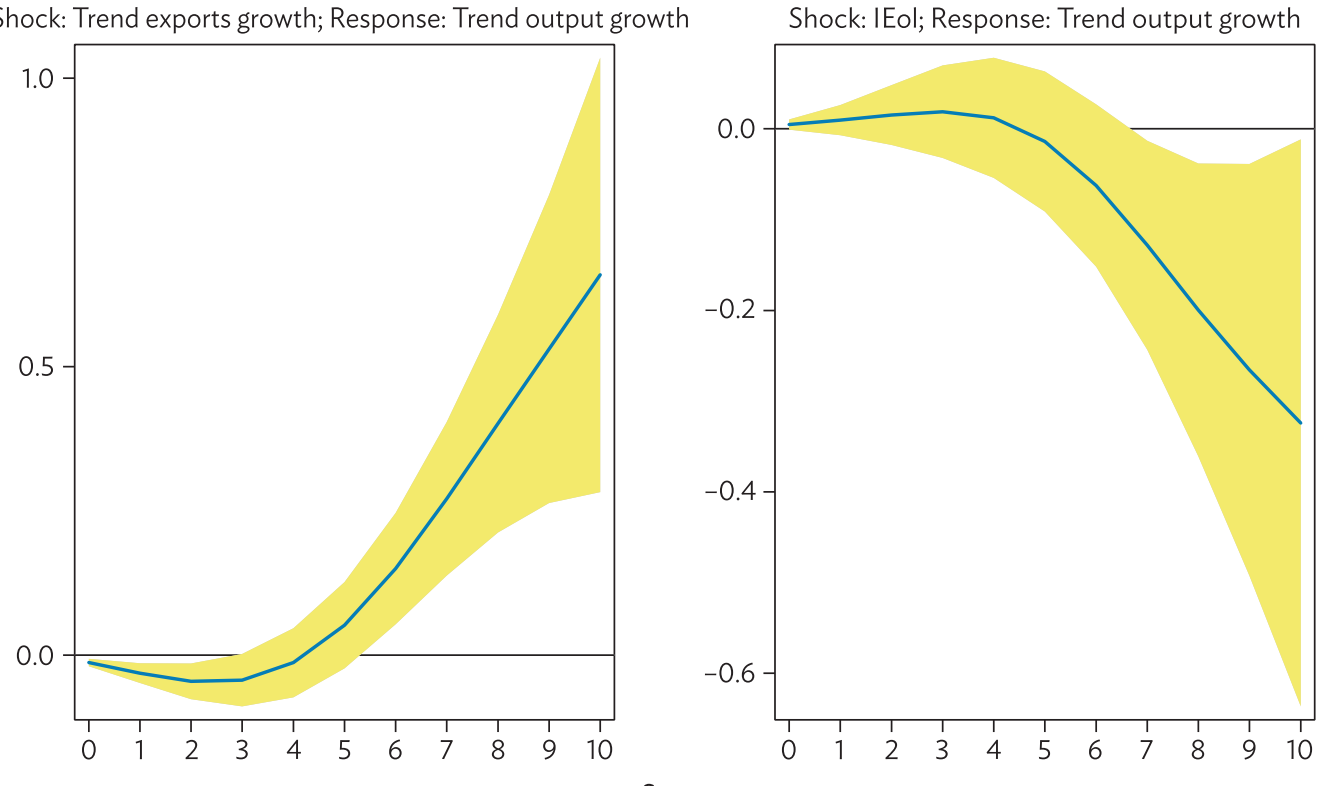

Step

$90 \% \mathrm{Cl} \quad$ Orthogonalized IRF

$\mathrm{Cl}$ = confidence interval, IEOI = income elasticity of imports, IRF = impulse response function. Source: Authors.

To sum up, together with the evidence gathered in the previous subsection, the outcome of our VAR-based analysis is in line with the view that the PRC's long-run growth performance can be closely associated with a growth process underpinned by export growth and, more specifically, driven by the dynamics of its BOPE growth rate. Seen in this light, the significant decrease in the PRC's trend growth rate from the mid-2000s onwards is primarily explained by demand-side factors, i.e., the global trade slowdown and the associated fall in the PRC's exports growth rate and BOPE growth rate. These dynamics may be (at least partly) cyclical but, just like for the PRC's rise to become a major world exporter, structural factors may also be playing an important role-this casts doubts on whether the PRC's trend growth can return to the fast growth rates that characterized the years before the Great Financial Crisis. According to the BOPE growth approach, the answer to this question depends critically on the role played by nonprice competition, encapsulated in the value of the income elasticity of imports $\pi_{t}$. Thus, investigating the possible determinants of $y_{B t}$ and $\pi_{t}$ becomes crucial from an economic policy viewpoint - a task we turn to in the next section. 


\section{THE DETERMINANTS OF THE PEOPLE'S REPUBLIC OF CHINA'S BALANCE-OF- PAYMENTS EQUILIBRIUM GROWTH RATE AND THE INCOME ELASTICITY OF IMPORTS: A BAYESIAN MODEL AVERAGING APPROACH}

Faced with the uncertainty of determining a priori the determinants of economic growth, several studies have recently implemented various model selection procedures that help ascertain which variables are "robustly" correlated with economic growth (e.g., Sala-i-Martin, Doppelhofer, and Miller 2004; Lanzafame 2016). In this paper, we rely on one such methodology-specifically, the BMA approach developed by Magnus, Powell, and Prüfer (2010) for estimation of classical linear regression models with uncertainty about the choice of the explanatory variables, to investigate the determinants of the PRC's BOPE growth rate and of the income elasticity of imports. We saw in the previous section that both varied significantly in the estimation period.

This estimator is based on a classical linear regression framework with two subsets of explanatory variables: (i) "focus regressors." These are explanatory variables always included in the model because of theoretical reasons or other considerations about the phenomenon under investigation; and (ii) "auxiliary regressors." These are additional explanatory variables whose inclusion in the model is less certain. The problem of model uncertainty and variable selection arises because different subsets of auxiliary regressors could be excluded from the model to improve (in the mean squared error sense) the unrestricted ordinary least squares estimates. When there are $k^{2}$ auxiliary regressors, the number of possible models to be considered is $2^{k_{2}}$.

The BMA estimator provides a coherent method of inference on the regression parameters of interest, by taking explicit account of the uncertainty due to both the estimation and the model selection steps. This Bayesian estimator uses conventional noninformative priors on the focus parameters and the error variance, and a multivariate Gaussian prior on the auxiliary parameters. The unconditional BMA estimates are obtained as a weighted average of the estimates from each of the possible models in the model space, with weights proportional to the marginal likelihood of the dependent variable in each model. An auxiliary regressor is considered to be robust if the $t$ ratio on its coefficient is greater than one in absolute value or, equivalently, the corresponding one standard error band does not include zero. Alternatively, researchers can rely on their posterior inclusion probabilities (pip). Specifically, Masanjala and Papageorgiou (2008) suggest that a posterior inclusion probability of 0.5 corresponds approximately to a $t$ ratio of one in absolute value.

\section{Data and Empirical Analysis}

Our selection of potential determinants of $y_{B t}$ and $\pi_{t}$ is based on insights from the international trade literature. In particular, focusing on the trade slowdown that followed the Great Recession, several recent studies (e.g., Hong et al. 2016, Martinez-Martin 2016) highlight a number of possible channels that could affect the volume of international trade and the trade elasticities. Based on data availability, we consider the following:

(i) The composition of aggregate demand (AD). The various $A D$ components are characterized by different import intensities (e.g., investment and exports are typically more import intensive than consumption), so that the same level or growth rate of output and 
aggregate demand can give rise to different import volumes and, thus, a different IEol. ${ }^{16}$ As discussed earlier, this intuition is the basis for the relationship embedded in equation (5) (BOPE approach) and the reason why the BOPE growth model is an appropriate framework to study long-run growth. Our BMA analysis takes account of this by controlling not only for the various components of $A D$ (i.e., exports, investment, consumption, government expenditure) but also for the determinants of the latter and in relation to their specific origin. The Chang et al. (2016) dataset is particularly suitable for this type of analysis, as it provides information on the features of income allocation by various agents in the economy (e.g., households, government, etc.), as well as the structural composition of the AD. These features can be expected to play a significant role in determining both $y_{B t}$ and $\pi_{t}$.

(ii) Global value chains (GVCs). GVCs affect significantly global trade dynamics and the PRC, which uses a significant share of imported goods to produce exports, is at the center of many GVCs. Following Martinez-Martin (2016), we use the share of intermediate goods in total imports as a proxy for the PRC's degree of integration into GVCs.

(iii) Inflows of foreign direct investment (FDI). The stocks of inward FDI can have a substitution effect on the domestic demand for imports, thus affecting the IEol. We control for this by introducing in our BMA analysis the share of inward FDI in total value added.

(iv) Trade barriers. All else constant, protectionist measures (for example, nontariff barriers such as quality standards or health regulations) can reduce trade volumes and, consequently, affect $y_{B t}$ and $\pi_{t}$. Following Martinez-Martin (2016), we control for this by relying on an index of Temporary Trade Barriers (TTBs) constructed by Bown (2012).

The BMA analysis of the determinants of $y_{B t}$ and $\hat{\pi}_{t}$ is carried out with a total of 17 potentially robust regressors, listed in Table 3 . We initially considered a larger number of possible determinants, fully exploiting all the information included in the Chang et al. (2016) dataset. However, many variables in the dataset can be considered as close alternatives, so that several of these were dropped from the analysis because of collinearity -including Bown's TTBs index.

The BMA results are reported in Tables 4 and 5. Table 4 focuses on the robust determinants of $y_{B t}$ - thus, we include the trend growth rate of exports as a focus regressor, while the other 16 possible determinants of the BOPE growth rate are considered as auxiliary regressors. As can be seen, nine variables (shown in bold) were selected by the BMA approach as robust determinants of the PRC's $y_{B t}$, under either of the abovementioned criteria, i.e., a $t$ ratio higher than one in absolute value, or a pip value greater than 0.5 . The labor income share (lys), the average real wage (In_avwr), household ( $h h c$ ) and government consumption ( $g c$ ) all enter with a negative sign, as expected. As household incomes and the share of consumption in total value added increase, ceteris paribus, the IEol rises too, thus lowering the BOPE growth rate. The same reasoning can be used to interpret the positive sign on the coefficient of the saving rates of nonfinancial institutions (sr_nfe), as well as of financial institutions (sr_fi). Meanwhile, for the remaining robust regressors we find a positive sign in the case of fixed asset investment (fai), and a negative sign for gross fixed capital formation of the whole economy ( $g k f$ ) and gross fixed capital formation of the private sector ( $g f k f \_p s$ ). The interpretation of these results is less clear cut, at least a priori. As mentioned above, as an import-intensive component of AD, investment

16 Building on this, Bussière et al. (2013) have recently proposed to analyze trade dynamics and trade elasticities relying on their relationship with an import Intensity-Adjusted Demand (IAD), rather than GDP (or internal demand). They show that the IAD turns out to be very useful in explaining the so-called Great Trade Collapse of 2008-2009. 
(and, thus, capital accumulation) increases the IEol. At the same time, however, investment can be expected to have a positive impact on the economy's export capability and performance. The overall impact on $y_{B t}$, therefore, is an empirical question-in the case of the PRC, the positive effects on export growth appears to exceed that on the IEol, only in the case of fixed asset investment.

Table 3: Variables and Data Sources

\begin{tabular}{|c|c|c|}
\hline Variable & Description & Source \\
\hline \multicolumn{3}{|c|}{ List of variables used for the estimation of $y_{B t}$} \\
\hline$m_{t}^{T}$ & Trend growth rate of imports & $\begin{array}{l}\text { Merchandise: Trade value, volume, unit value, } \\
\text { terms of trade indices and purchasing power index } \\
\text { of exports, annual, 1980-2016: UNCTAD }\end{array}$ \\
\hline$r p_{t}$ & Relative price of imports & $\begin{array}{l}\text { Merchandise: Trade value, volume, unit value, } \\
\text { terms of trade indices and purchasing power index } \\
\text { of exports, annual, 1980-2016: UNCTAD }\end{array}$ \\
\hline$y_{t}^{T}$ & Trend growth rate of output & Chang et al. (2016) \\
\hline$x_{t}^{T}$ & Trend growth rate of exports & $\begin{array}{l}\text { Merchandise: Trade value, volume, unit value, } \\
\text { terms of trade indices and purchasing power index } \\
\text { of exports, annual, 1980-2016: UNCTAD }\end{array}$ \\
\hline \multicolumn{3}{|c|}{ List of potential determinants of $y_{B t}$ and $\hat{\pi}_{t}$ included in the BMA analysis } \\
\hline lys & Labor income share in total value added & Chang et al. (2016) \\
\hline$s r$ & Saving rate as percentage of total value added: total & Chang et al. (2016) \\
\hline sr_hh & Saving rate as percentage of total value added: households & Chang et al. (2016) \\
\hline sr_nfe & $\begin{array}{l}\text { Saving rate as percentage of total value added: non-financial } \\
\text { enterprises }\end{array}$ & Chang et al. (2016) \\
\hline$s r_{-} f i$ & $\begin{array}{l}\text { Saving rate as percentage of total value added: financial } \\
\text { institutions }\end{array}$ & Chang et al. (2016) \\
\hline ln_avrw & Logarithm of aggregate average real wages & Chang et al. (2016) \\
\hline fai & Fixed asset investment as percentage of total value added & Chang et al. (2016) \\
\hline hhc & $\begin{array}{l}\text { Household consumption by expenditure as percentage of } \\
\text { total value added }\end{array}$ & Chang et al. (2016) \\
\hline$g c$ & $\begin{array}{l}\text { Government consumption by expenditure as percentage of } \\
\text { total value added }\end{array}$ & Chang et al. (2016) \\
\hline Gkf & Gross capital formation as percentage of total value added & Chang et al. (2016) \\
\hline \multicolumn{3}{|c|}{ List of potential determinants of $y_{B t}$ and $\hat{\pi}_{t}$ included in the BMA analysis } \\
\hline$g f k f$ & $\begin{array}{l}\text { Gross fixed capital formation as percentage of total value } \\
\text { added. }\end{array}$ & Chang et al. (2016) \\
\hline$g f k f-g o v$ & $\begin{array}{l}\text { Gross fixed capital formation as percentage of total value } \\
\text { added: government. }\end{array}$ & Chang et al. (2016) \\
\hline$g f k f \_p s$ & $\begin{array}{l}\text { Gross fixed capital formation as percentage of total value } \\
\text { added: private sector, excluding government, households, } \\
\text { SOEs, and other non-SOEs. }\end{array}$ & Chang et al. (2016) \\
\hline$g f k f \_h h$ & $\begin{array}{l}\text { Gross fixed capital formation as percentage of total value } \\
\text { added: households. }\end{array}$ & Chang et al. (2016) \\
\hline fdi & $\begin{array}{l}\text { Inward foreign direct investment as percentage of total } \\
\text { value added. }\end{array}$ & World Development Indicators: World Bank. \\
\hline$g v c$ & Intermediate goods as percentage of total imports & $\begin{array}{l}\text { Bilateral Trade in Goods by Industry and } \\
\text { End-use (BTDIxE), ISIC Rev.4: OECD }\end{array}$ \\
\hline
\end{tabular}


Table 4: Bayesian Model Averaging Estimates of Robust Determinants of $y_{B t}$

\begin{tabular}{lcrrrrr}
\hline & Coefficient & Std. Err. & t_stat & pip & \multicolumn{2}{c}{ 1-Std. Err. Bands } \\
\hline$x_{t}^{T}$ & 0.238 & 0.194 & 1.23 & 1.00 & 0.045 & 0.432 \\
lys & -0.511 & 0.358 & -1.43 & 0.73 & -0.869 & -0.152 \\
sr & 0.120 & 0.293 & 0.41 & 0.25 & -0.173 & 0.414 \\
sr_hh & -0.028 & 0.145 & -0.19 & 0.11 & -0.173 & 0.118 \\
sr_nfe & 0.339 & 0.341 & 0.99 & 0.59 & -0.003 & 0.680 \\
sr_fi & 2.192 & 1.979 & 1.11 & 0.66 & 0.213 & 4.171 \\
In_avrw & -12.858 & 2.684 & -4.79 & 1.00 & -15.542 & -10.174 \\
fai & 0.429 & 0.278 & 1.54 & 0.82 & 0.151 & 0.707 \\
hhc & -0.862 & 0.620 & -1.39 & 0.86 & -1.482 & -0.241 \\
gc & -0.891 & 0.756 & -1.18 & 0.65 & -1.647 & -0.135 \\
gkf & -0.890 & 0.775 & -1.15 & 0.65 & -1.666 & -0.115 \\
gfkf & -0.022 & 0.217 & -0.10 & 0.22 & -0.238 & 0.195 \\
gfkf_gov & -0.375 & 0.769 & -0.49 & 0.36 & -1.144 & 0.394 \\
gfkf_ps & -0.272 & 1.419 & -0.19 & 0.57 & -1.691 & 1.147 \\
gfkf_hh & 0.031 & 0.286 & 0.11 & 0.29 & -0.254 & 0.317 \\
fdi & -0.002 & 0.126 & -0.01 & 0.10 & -0.128 & 0.124 \\
gkc & -0.001 & 0.059 & -0.01 & 0.15 & -0.060 & 0.059 \\
Model space: 65536 models & & & & & & \\
\hline Source:Author & & & & & &
\end{tabular}

Source: Authors.

Table 5 reports the BMA results from our search for robust determinants of $\hat{\pi}_{r}$. Recall that the import elasticity of imports captures the nonprice competitiveness attributes of the PRC's imports. One would expect the import elasticity to have increased over time, reflecting among other things the increase in imports of machinery (which reached about 45\% of total imports in the early 1990s and in the early 2000s) and of sophisticated consumer products, as the PRC's income increased. This is indeed the PRC's experience until the early 2000s. Recall that since then, it has undergone a significant decline, the result of a faster decline in the growth rate of exports than in the income elasticity of imports.

Since in this case no clear theoretical approach dictated the number of possible focus regressors, all the 17 variables in the analysis were considered as auxiliary regressors. Out of these, the BMA analysis selected five as robust determinants of the IEol: the trend exports growth rate $\left(x_{t}^{T}\right)$, the average real wage (ln_avwr), household consumption ( $h h c$ ), which enter with the expected positive sign, gross fixed capital formation of the private sector (gfkf_ps), and the household sector (gfkf_hh), both with a negative sign.

Overall, the picture that emerges from the BMA analysis is one in which, since the early $1980 \mathrm{~s}$, the trajectory of the BOPE growth rate in the PRC has been primarily influenced by the dynamics of particular components of aggregate income and aggregate demand. As neatly summarized in the simple specification of the BOPE growth rate, export growth has acted as an engine of growth and, at the same time, as a check on output growth via its direct and indirect effects on import growth and the BOPE. 
Table 5: Bayesian Model Averaging Estimates of Robust Determinants of $\hat{\pi}_{t}$

\begin{tabular}{lcccccc}
\hline & Coefficient & Std. Err. & t_stat & pip & \multicolumn{2}{c}{ 1-Std. Err. Bands } \\
\hline$x_{t}^{T}$ & 0.048 & 0.028 & 1.73 & 0.84 & 0.020 & 0.075 \\
lys & 0.009 & 0.036 & 0.25 & 0.14 & -0.027 & 0.045 \\
sr & 0.003 & 0.033 & 0.09 & 0.18 & -0.030 & 0.036 \\
sr_hh & 0.011 & 0.037 & 0.29 & 0.15 & -0.026 & 0.048 \\
sr_nfe & 0.008 & 0.023 & 0.35 & 0.18 & -0.015 & 0.030 \\
sr_fi & -0.003 & 0.069 & -0.04 & 0.11 & -0.072 & 0.066 \\
ln_avrw & 2.227 & 0.801 & 2.78 & 0.96 & 1.426 & 3.028 \\
fai & -0.016 & 0.029 & -0.54 & 0.33 & -0.045 & 0.013 \\
hhc & 0.228 & 0.067 & 3.41 & 0.96 & 0.161 & 0.295 \\
gc & 0.026 & 0.076 & 0.35 & 0.18 & -0.050 & 0.103 \\
gkf & 0.015 & 0.042 & 0.35 & 0.25 & -0.0277 & 0.057 \\
gfkf & 0.016 & 0.033 & 0.47 & 0.28 & -0.017 & 0.049 \\
gfkf_gov & 0040 & 0.106 & 0.38 & 0.23 & -0.066 & 0.146 \\
gfkf_ps & -0.184 & 0.220 & -0.84 & 0.54 & -0.404 & 0.036 \\
gfkf_hh & -0.126 & 0.093 & -1.35 & 0.74 & -0.219 & -0.033 \\
fdi & -0.004 & 0.031 & -0.13 & 0.09 & -0.035 & 0.027 \\
grc & -0.000 & 0.012 & -0.04 & 0.12 & -0.012 & 0.011 \\
Model space: 131072 models & & & & & & \\
\hline Source:Aushos & & & & & & \\
\hline
\end{tabular}

Source: Authors.

Finally, it is worth noting that foreign direct investment inflows ( $f d i)$ does not turn out to be one of the robust regressors in our BMA analysis. This may be due to the fact that these inflows affect the BOPE growth rate through the effects on capital accumulation and knowledge spillovers, picked up in our analysis via the physical capital accumulation proxies and the gvc index (intermediate goods as percentage of total imports). Indeed, once the latter variables are taken out of the set of robust regressors, fdi is selected as significant by the BMA estimator. Supporting this view, Granger-causality tests confirm statistically significant causality running from fdi to gross fixed capital formation as percentage of total value added ( $g f k$ ), gross fixed capital formation as percentage of total value added households (gfkf_hh), and intermediate goods as percentage of total imports $(g \vee c) .{ }^{17}$

17 To save space, these results are not included in the paper: They are available from the authors upon request. 


\section{CONCLUSIONS}

This paper has provided an analysis of the PRC's growth since the early 1980s, consistent with an export-led growth explanation. The PRC's remarkable growth performance since reforms began has been associated to a similarly significant growth rate of its exports. In this paper we have argued that a comprehensive analysis of the PRC's long-run growth can be understood as an export-led growth process, according to which the PRC had to export to pay for its import needs, i.e., the long-term constraint on growth posed by the need to maintain BOPE. We referred to the maximum growth rate the country could achieve without running into BOP problems, as the BOPE growth rate.

Based on this, we have implemented a time-varying parameter approach to estimate the PRC's BOPE growth rate. We find that the average value of the PRC's $y_{B t}$ estimate for 1981-2016 is about $11 \%$, although it varied significantly over time and has declined notably after 2007 . This rate approximates very well the PRC's long-run growth rate trend. Today, the PRC's BOPE is a much lower $5.9 \%$. Standard tests support the hypothesis that trend growth in the PRC is significantly associated to the BOPE growth rate, and this evidence is reinforced by a VAR-based analysis relying on Grangercausality tests and Impulse Response Functions. Finally, our search for the determinants of the PRC's BOPE growth rate, based on the BMA approach, underlines the role of aggregate demand composition as the main driving force, both for its direct effects on the income elasticity of imports and the indirect effects on exports growth via capital accumulation (and, in particular, fixed asset investment).

The upshot of our analysis is that the future dynamics of the PRC's BOPE growth rate, and thus its long-run growth performance, will depend on the features of its ongoing structural change. In particular, if the expected transition toward a more services-based and consumption-driven economy occurs at a steady pace, the PRC is likely to gradually follow the standard path toward 'economic maturity,' associated with a slowdown in fixed asset investment, a rise in the labor income share, and a higher share of private consumption in GDP. All of this points to a rise in $\pi_{t}$ for a given export growth rate, and to a lower BOPE growth rate. Indeed, the PRC's BOPE growth rate has declined significantly

and fast during the last few years. Seen in this light, the PRC's growth deceleration since the onset of the Great Financial Crisis may, indeed, be the beginning of a New Normal. 


\section{REFERENCES}

Aghion, Philippe, and Peter Howitt. 2007. "Capital, Innovation, and Growth Accounting." Oxford Review of Economic Policy 23 (1): 79-93.

Alonso, Jose Antonio. 1999. "Growth and the External Constraint: Lessons from the Spanish Case." Applied Economics 31 (2): 245-53.

Ang, James B., Jakob B. Madsen, and Peter E. Robertson. 2015. "Export Performance of the Asian Miracle Economies: The Role of Innovation and Product Variety." Canadian Journal of Economics 48 (1): 273-309.

Bagnai, Alberto. 2010. "Structural Changes, Cointegration and the Empirics of Thirlwall's Law." Applied Economics 42 (10): 1315-29.

Bairam, Erkin I. 1993. "Static versus Dynamic Specifications and the Harrod Foreign Trade Multiplier." Applied Economics 25 (6): 739-42.

Borensztein, Eduardo, and Jonathan D. Ostry. 1996. “Accounting for China's Economic Performance." The American Economic Review, Papers and Proceedings 86 (2): 224-28.

Bown, Chad P. 2012. Temporary Trade Barriers Database. Washington DC: The World Bank.

Brandt, Loren, and Xiaodong Zhu. 2010. “Accounting for China's Growth.” University of Toronto, Department of Economics Working Paper No. 394.

Bussière, Matthieu, Giovanni Callegari, Fabio Ghironi, Giulia Sestieri, and Norihiko Yamano. 2013. "Estimating Trade Elasticities: Demand Composition and the Trade Collapse of 2008-2009." American Economic Journal: Macroeconomics 5 (3): 118-51.

Center for International Development (http://atlas.cid.harvard.edu/).

Chang, Chun, Kaiji Chen, Daniel F. Waggoner, and Tao Zha. 2016. "Trends and Cycles in China's Macroeconomy." In NBER Macroeconomics Annual 2015, Volume 30, edited by Martin Eichenbaum, Jonathan Parker, 1-84. University of Chicago Press.

Chow, Gregory C. 1993. "Capital Formation and Economic Growth in China." Quarterly Journal of Economics 108 (3): 809-42.

_. 2006. “New Capital Estimates for China: Comments.” China Economic Review 17 (2): 186-92.

Corbae, Dean, and Sam Ouliaris. 2006. "Extracting Cycles from Nonstationary Data." In Econometric Theory and Practice: Frontiers of Analysis and Applied Research, edited by Dean Corbae, Steven Durlauf, and Bruce E. Hansen. New York: Cambridge University Press, New York.

Corbae, Dean, Sam Ouliaris, Peter C. B. Phillips. 2002. "Band Spectral Regression with Trending-Data.” Econometrica 70 (3): 1067-109. 
Dixon, R. J., and Anthony P. Thirlwall. 1975. "A Model of Regional Growth Rate Differences on Kaldorian Lines.” Oxford Economic Papers 27 (2): 201-14.

Elliott, Graham, Thomas J. Rothenberg, and James H. Stock. 1996. "Efficient Tests for an Autoregressive Unit Root." Econometrica 64 (4): 813-36.

Feder, Gershon. 1983. “On Exports and Economic Growth.” Journal of Development Economics 12 (1-2): 59-73.

Felipe, Jesus, Utsav Kumar, Norio Usui, and Arnelyn Abdon. 2013. "Why Has China Succeeded? And Why It Will Continue to Do So.” Cambridge Journal of Economics 37 (4): 791-818.

Felipe, Jesus, and John S. L. McCombie. 2001. "Biased Technical Change, Growth Accounting, and the Conundrum of the East Asian Miracle." Journal of Comparative Economics 29 (3): 542-65.

- 2002. "Productivity in China Before and After 1978 Revisited. Zagreb International Review of Economics and Business 5 (1): 17-43.

Granger, Clive W. J. 1969. "Investigating Causal Relations by Econometric Models and Cross-Spectral Methods.” Econometrica 37 (3): 424-38.

Guarini, Guilio, and Gabriel Porcile. 2016. "Sustainability in a Post-Keynesian Growth Model for an Open Economy.” Ecological Economics 126: 14-22.

Harvey, Andrew C. 1989. Forecasting, Structural Time Series Models and the Kalman Filter. Cambridge: Cambridge University Press.

Hausmann, Ricardo, Jason Hwang, and Dani Rodrik. 2007. "What You Export Matters." Journal of Economic Growth 12 (1): 1-25.

Heytens, Paul, and Harm Zebregs. 2003. "How Fast Can China Grow?" In China Competing in the Global Economy, edited by Wanda Tseng, Markus Rodlauer. Washington, DC: International Monetary Fund.

Holz, Carsten. 2006. "Response to Gregory C. Chow's 'New Estimates for China' Comments." China Economic Review 17 (2): 193-97.

Hong, Gee Hee, Jaewoo Lee, Wei Liao, and Dulani Seneviratne. 2016. "China and Asia in Global Trade Slowdown." IMF Working Paper No. WP/16/105.

Hu, Zuliu F., and Mohsin S. Khan. 1997. "Why is China Growing So Fast?” IMF Staff Papers 44: 103-31.

Hussain, M. Nureldin. 2004. "The Balance of Payments Constraints and Growth Rate Differences among African and East Asian Economies." In Essays on Balance of Payment Constrained Growth, edited by John S. L. McCombie, Anthony P. Thirlwall, 220-44. Routledge.

Islam, Nazrul, Erbiao Dai, and Hiroshi Sakamoto. 2006. "Sources of Growth." In Economic Growth, Transition and Globalization in China, edited by Yanrui Wu, 13-60. Northampton: Edward Elgar. 
Jeon, Yongbok. 2009. "Balance-of-Payment Constrained Growth: The Case of China, 1979-2002." International Review of Applied Economics 23 (2): 135-46.

Kwiatkowski, Denis, Peter C. B. Phillips, Peter Schmidt, and Yongcheol Shin. 1992. "Testing the Null Hypothesis of Stationarity Against the Alternative of a Unit Root: How Sure are we that Economic Time Series Have a Unit Root?" Journal of Econometrics 54 (1-3): 159-78.

Lanzafame, Matteo. 2014. "The Balance of Payments-Constrained Growth Rate and the Natural Rate of Growth: New Empirical Evidence.” Cambridge Journal of Economics 38 (4): 817-38.

—. "Potential Growth in Asia and Its Determinants: An Empirical Investigation." Asian Development Review 33 (2): 1-27.

Lin, Justin Yifu, and Fan Zhang. 2015. "Sustaining Growth of the People's Republic of China." Asian Development Review 32 (1): 31-48.

Lin, Justin Yifu, Peter J. Morgan, and Guanghua Wan, eds. 2018a. Slowdown in the People's Republic of China: Structural Factors and the Implications for Asia. Tokyo: Asian Development Bank Institute.

2018b. "Factors Affecting the Outlook for Medium-to Long-Term Growth in the People's Republic of China." In Slowdown in the People's Republic of China: Structural Factors and the Implications for Asia, edited by Justin Yifu Lin, Peter J. Morgan, Guanghua Wan, 220-49. Tokyo: Asian Development Bank Institute.

Magnus, Jan R., Owen Powell, and Patricia Prüfer. 2010. "A Comparison of Two Model Averaging Techniques with an Application to Growth Empirics." Journal of Econometrics 154 (2): 139-53.

Martinez-Martin, Jaime. 2016. "Breaking Down World Trade Elasticities: A Panel ECM Approach.” Banco de España Working Paper No. 1614.

Masanjala, Winford H., and Chris Papageorgiou. 2008. "Rough and Lonely Road to Prosperity: A Reexamination of the Sources of Growth in Africa Using Bayesian Model Averaging." Journal of Applied Econometrics 23 (5): 671-82.

Mayer, Jörg. 2017. "How Could the South Respond to Secular Stagnation in the North?" The World Economy 40 (2): 314-35.

McCombie, John S. L., and Anthony P. Thirlwall. 1994. Economic Growth and the Balance of Payments Constraint. Basingstoke: Macmillan.

Sala-i-Martin, Xavier, Gernot Doppelhofer, and Ronald I. Miller. 2004. "Determinants of Long-Term Growth: A Bayesian Averaging of Classical Estimates (BACE) Approach.” American Economic Review 94 (4): 813-35.

Sims, Christopher. 2001. "Comments on Sargent and Cogley's Evolving Post World War II US Inflation Dynamics.” NBER Macroeconomics Annual 16: 373-79. 
Thirlwall, Anthony P. 1979. "The Balance of Payments Constraint as an Explanation of International Growth Rate Differences.” Banca Nazionale del Laboro Quarterly Review 32 (128): 45-53.

Tingvall, Patrick Gustavsson, and Christer Ljungwall. 2012. "Is China Different? A Meta-Analysis of Export-Led Growth.” Economics Letters 115 (2): 177-79.

Tsui, Kai-Yuen, Tien-Tung Hsueh, and Thomas G. Rawski. 1995. Productivity, Efficiency and Reform in China's Economy. Hong Kong, China: Chinese University of Hong Kong.

Yao, Yang. 2018. "Will the People's Republic of China be Able to Avoid the Japan Syndrome?" In Slowdown in the People's Republic of China: Structural Factors and the Implications for Asia, edited by Justin Yifu Lin, Peter J. Morgan, Guanghua Wan, 29-60. Tokyo: Asian Development Bank Institute.

Young, Alwyn. 2000. "Gold into Base Metals: Productivity Growth in the People's Republic of China during the Reform Period." NBER Working Paper No. 7856.

Zhang, Kevin Honglin. 2015. "What Drives Export Competitiveness? The Role of FDI in Chinese Manufacturing." Contemporary Economic Policy 33 (3): 499-512.

Zivot, Eric, and Donald W. K. Andrews. 1992. Further Evidence on the Great Crash, the Oil Price Shock, and the Unit-Root Hypothesis. Journal of Business \& Economic Statistics 10 (3): 251-70. 


\section{The PRC's Long-Run Growth through the Lens of the Export-Led Growth Model}

Using the concept of the balance-of-payments equilibrium (BOPE) growth rate, this papers tests the proposition that the People's Republic of China's (PRC) remarkable growth performance over the last 3 decades was a case of export-led growth. Results indicate that the PRC's actual long-run growth is well approximated by its BOPE growth rate. The analysis has important implications to understand the PRC's transition to a "New Normal" of a lower growth rate.

\section{About the Asian Development Bank}

ADB is committed to achieving a prosperous, inclusive, resilient, and sustainable Asia and the Pacific, while sustaining its efforts to eradicate extreme poverty. Established in 1966, it is owned by 67 members48 from the region. Its main instruments for helping its developing member countries are policy dialogue, loans, equity investments, guarantees, grants, and technical assistance. 